\title{
Quatro olhares sobre a dramaturgia
}

\section{Ana Campos}

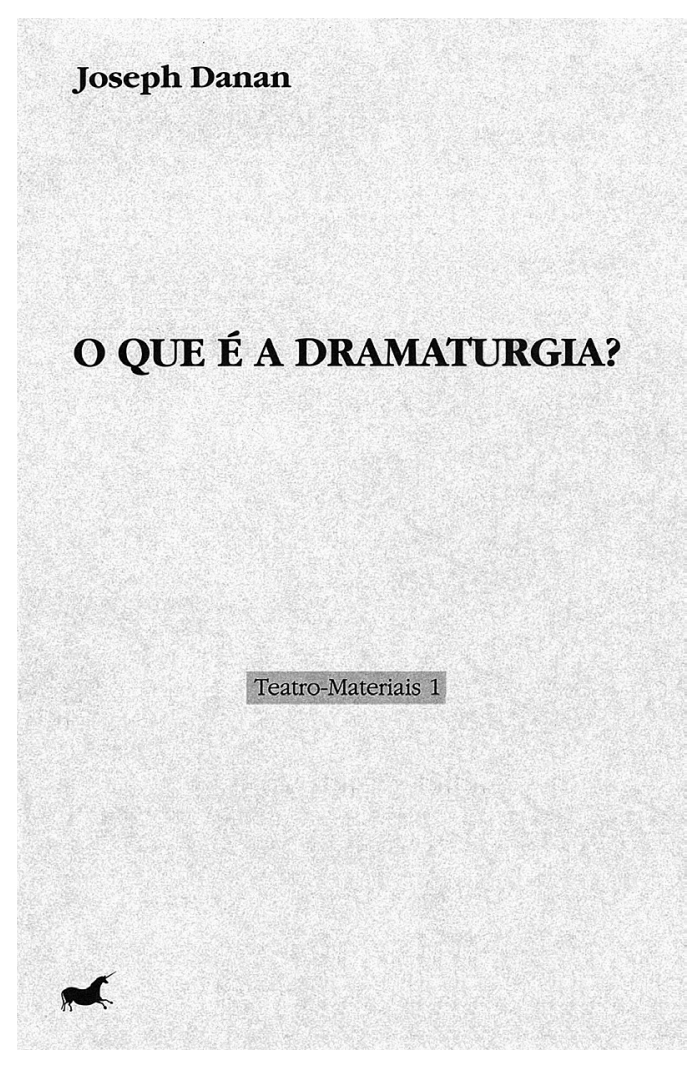

Joseph Danan, $O$ que é a dramaturgia?, trad. Luís Varela, Évora, Editora Licorne, TeatroMateriais 1, 2010, $95 \mathrm{pp}$.

Dirigida por Christine Zurbach, a colecção Teatro-Materiais da editora eborense Licorne propõe-se trazer a todos os que se debruçam sobre o teatro, independentemente do seu grau de especialização, um conjunto de ensaios que analisam reflexivamente a prática dramática contemporânea.

Inaugura a colecção, a obra 0 que é a dramaturgia? de Joseph Danan, director do Institut d'Etudes Théâtrales (Paris III - Sorbonne Nouvelle), dramaturgo e dramaturgista. Da sua colaboração regular com o Théâtre des 2 Rives aliada à sua prática académica, nasceu este ensaio onde o autor se debruça sobre o tão controverso e indefinivel conceito de dramaturgia no teatro contemporâneo como pretexto para o interrogar. Inicia a sua reflexão pela separação do conceito em dois, designando-os por dramaturgia 1 e dramaturgia 2. Entende a dramaturgia 1, conceito pacificamente aceite durante anos, como a arte de escrever peças de teatro. Esta ideia tem-se vindo a

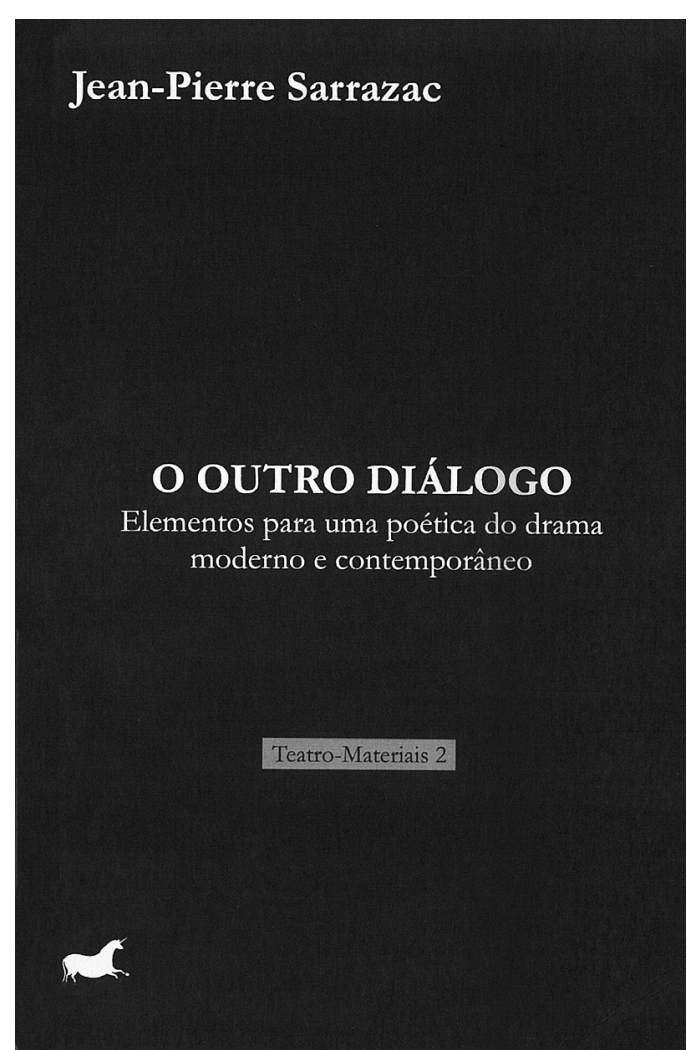

Jean-Pierre Sarrazac, $O$ outro diálogo: Elementos para uma poética do drama moderno e contemporâneo, trad. Luís Varela, Évora, Editora Licorne, Teatro-Materiais 2, 2011, 89 pp.

complexificar à medida que o drama progressivamente tem vindo a ser afastado do teatro. Por outro lado, entende a dramaturgia 2 como a passagem ao palco de peças de teatro. Esta distinção, que podemos ter como evidente, torna-se bastante difusa já que a dramaturgia 2 está também contida na dramaturgia 1. Aceitando que estas duas definições são manifestamente insuficientes, o autor vai passar em revista a evolução dos conceitos desde a Dramaturgia de Hamburgo (1767-1769) de Lessing, até às práticas contemporâneas como a dança e a performance. Constata, porém, que, já naquele teórico alemão, a dramaturgia estava intimamente ligada à passagem ao palco da obra dramática, antes mesmo do nascimento do conceito de encenação.

Paralelamente, Joseph Danan entra em diálogo com os autores das propostas mais recentes de definição de dramaturgia, como Benard Dort e o seu conceito operativo de "estado de espírito dramatúrgico", tentando aproveitar
Ana Campos

é doutoranda em Estudos de Teatro na Faculdade de Letras da Universidade de Lisboa e investigadora do Centro de Estudos de Teatro da mesma Faculdade. 
de cada proposta aquilo que pode ser mais útil para uma estabilização desta prática. Se até aqui a palavra dramaturgia foge de qualquer tentativa de fixação, a partir do momento em que se procura encontrar o seu responsável no modo de fazer teatro contemporâneo, ela torna-se quase inatingivel. Pergunta, com pertinência, se não existirão no texto original, e nas encenações possíveis, eventuais elementos invariáveis aos quais qualquer encenação não pode fugir sob pena de já não estar a encenar aquele texto. 0 autor reconhece, contudo, que essa relação dialéctica implícita na dramaturgia, na prática actual, em que predomina a encenação, só faz sentido se for reformulada de cada vez que o texto é levado à cena. Como agravante, surge o facto de o texto prévio, caso exista, ser apenas um dos materiais entre muitos outros com que o espectáculo é construído, anulando-se assim a dramaturgia 1 e exigindo-se novas dimensões à dramaturgia 2. Tal reflexão conduz Danan a questionar para que serve a dramaturgia, afinal, e em que medida ela se distingue da encenação nas produções actuais, a que chama pós-dramáticas ou, como prefere, a-dramáticas.

0 volume seguinte da colecção é composto por cinco artigos já anteriormente publicados de Jean-Pierre Sarrazac, outro autor ligado à prática do teatro como dramaturgo e encenador e à reflexão teórica como académico. Neste conjunto de ensaios escritos em diálogo explícito com o pensamento contemporâneo, Sarrazac debruça-se sobre a noção de dramaturgia. Na "Carta a Benard Dort" com que o livro abre, Sarrazac explica o seu gosto pela dramaturgia, que entende como desmontagem dos textos dramáticos tendo em vista, sempre, a sua nova montagem no espectáculo, afirmando, tal como Dort, que a primazia está sempre no palco. Dort defendia, recordo, que passámos de uma revolução coperniciana nos palcos, em que o texto era o centro, para uma revolução einsteiniana em que todos os elementos se relacionam em posição relativa. Sarrazac propõe, nesta linha, uma reflexão em torno do que chama o drama-da-vida (em seu entender, progressivo, orgânico, limitado a uma jornada fatal) para o drama-navida (retrospectivo, objecto de montagem que abrange toda uma existência) que parte da premissa do desemparelhamento do teatro do drama. Na sua concepção de dramaturgia, esta tem vindo a perder terreno nos palcos na mesma medida em que o ganha nos estudos académicos. Tal como Danan, acredita que o "estado de espírito dramatúrgico" definido por Dort é um conceito operativo de extrema utilidade e sempre presente nos palcos, mesmo na actual polifonia das encenações. Ao mesmo tempo, rejeita a ideia proposta por Lehamann de "pós-dramático" exactamente pela premissa que traz na sua definição de ser ela própria "pós-dramática", pois o contexto cénico é, em si mesmo, sempre dramático, entendendo-se como drama a própria dimensão humana. Defende, portanto, uma mudança de paradigma do drama por oposição à ideia da sua morte. Entende o drama contemporâneo como uma forma rapsódica que não o anula enquanto drama. Tal reflexão desemboca na ideia de Abirached de que vivemos uma crise da mimesis da qual o esvaziamento completo das personagens é o aspecto mais visivel.

0 terceiro volume publicado pela colecção intitulase Tradução. Dramaturgia. Encenação, é dirigido por Christine Zurbach e Célia Caravela, e apresenta as comunicações, de natureza diversa e qualidade muito diferenciada, proferidas na primeira edição do Seminário homónimo, que teve lugar no dia 27 de Outubro de 2010 no âmbito dum projecto do Centro de História da Arte e Investigação Artística (CHAIA) da Universidade de Évora. Entre os estudos aqui publicados, destacaria a comunicação de António Henrique Conde, intitulada "Tradução dramatúrgica e ignição de escritas dramatúrgicas autóctones (1990-2010)". Nesta intervenção, o autor passa em revista as práticas dramatúrgicas particularmente no que concerne a tradução de teatro desde o início do século $X X$, passando pelo fechamento ao exterior e pela mitificação do passado português que representou o Estado Novo, para se centrar no aspecto, a meu ver mais importante para esta leitura, das práticas contemporâneas. Entende que, assistindo-se à regressão das utopias revolucionárias, nos anos 80 se optou pela exploração estética em detrimento da intervenção social, para na década seguinte o teatro, acompanhando o desenvolvimento europeista do país e a crença nas suas potencialidades inúmeras, se abrir tanto ao exterior como às emergentes dramaturgias nacionais. Na opinião de António Henrique Conde, no início do século XXI o teatro português tornou-se território de práticas restritas e muito especializadas, atingindo um grau de depuração e despojamento extremos ainda que com fraca visibilidade social e cultural. As características distintivas destas novas dramaturgias que surgem ao lado da importação contínua de dramaturgias estrangeiras seriam as seguintes: 


\section{Tradução Dramaturgia Encenação}

\author{
Org. \\ Christine Zurbach e Célia Caravela
}

\section{Anne Ubersfield}

\section{DS}

\section{TERMDS-CHAVE}

\section{IDA}

\section{ANÁLISE TEATHAL}

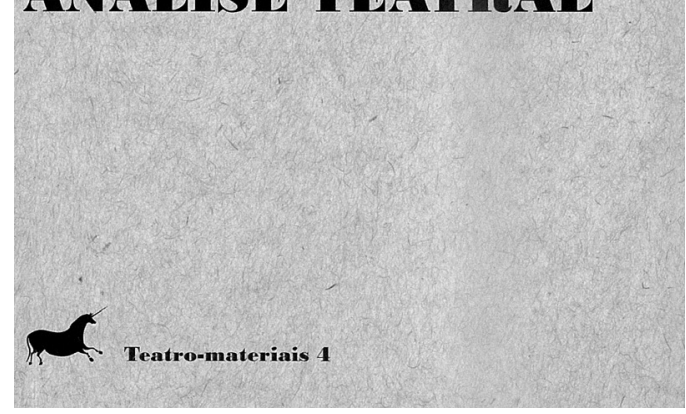

Anne Ubersfeld, Os termos-chave da análise teatral, trad. Luís Varela, Évora, Editora Licorne, Teatro-Materiais 4, 2012, $105 \mathrm{pp}$.

Dramaturgia. Encenação. (I), Évora, Editora Licorne, Teatro-Materiais 3, 2012,133 pp.

\footnotetext{
A linguagem é seca e quase de reprodução quotidiana, as situações dramáticas engendradas primam pela familiaridade reconhecivel, os trajectos dramáticos não reservam grandes surpresas ou tendem ao estático ou ao circular - criam-se espaços mentais de reflexão sobre temáticas próximas, capazes de tocar e conectar palco e públicos lafectos, matérias da sociabilidade corrente, aflorações de problemáticas da vida portuguesa actual, destituição de grandes valores ou questões filosóficas transcendentes), como se as personagens contemporâneas se expusessem perante interlocutores contemporâneos, mas sem que dessa conexão por via do teatro se buscassem mais do que constatações reticentes, sem qualquer didactismo ou ambição de despoletar soluções, polémicas - quase só uma reprodução dramatúrgica, teatralmente depurada nas formas, de supostos fragmentos da vida portuguesa actual, exterior ao espaço teatral, composta perante espectadores e deixada a vogar como interrogação menor (exemplificam-no algumas peças de Eiras, Lucas Pires, Vieira Mendes). (Zurbach / Caravela 2012: 70)
}

Encontramos, nesta análise, para além da interessante visão sobre as práticas de escrita para teatro actuais, uma visão da dramaturgia presa à produção de textos de teatro, muito conservadora e afastada de todas as propostas anteriores e completamente alheada do facto de estas dramaturgias conterem propostas de encenação menos textocêntricas do que se poderia julgar pela análise.

Da definição de cerca de cem termos-chave da análise textual feita por Anne Ubersfeld, sem cair na tentação de fixação de um conceito, mas antes analisando criticamente as várias propostas já apresentadas, interessou-me particularmente, na linha das obras já referidas, o conceito de dramaturgia. Segundo a autora, a definição de dramaturgia como produção de obras dramáticas já caiu em desuso, o que significa a rejeição da ideia de dramaturgia 1 de Joseph Danan e propõe três novas visões do conceito:

\footnotetext{
1- A dramaturgia é o estudo da construção do texto de teatro, por exemplo, A dramaturgia clássica em França, de J. Schérer, é o estudo da escrita e poética do teatro clássico.

2- Designa o estudo da escrita e da poética da representação. 3-É a actividade do dramaturgo no sentido alemão ou pós-brechtiano. Nesse sentido, a dramaturgia é o estudo concreto das relações do texto e da representação com a História, por um lado, e com a ideologia actual, por outro. A dramaturgia é então o estudo não só do texto e da representação, mas também da relação entre a representação e o público que a deve receber e compreender: implica, portanto, não dois mas três elementos. (Ubersfeld 2012: 39-40)
}

0 diálogo estabelecido entre estas quatro obras já publicadas é um dos pontos mais relevantes da colecção que permite ao público aceder de forma sistematizada a textos fragmentários, ainda que unidos pela reflexão em torno dos mesmos conceitos, que de outro modo seriam de difícil acesso, e ainda compreender as diferentes perspectivas que estão a ser debatidas neste momento, sobre noções tão fundamentais e tão difusas como a de dramaturgia. Estas obras pecam apenas pela ausência de uma revisão mais apurada do texto, o que cria um enorme contraste entre a sua qualidade e a forma como se dá a conhecer ao leitor. 